\title{
Determinants of self-perceived health for Canadians aged 40 and older and policy implications
}

William lan Andrew Bonner, Robert Weiler, Rotimi Orisatoki, Xinya Lu, Mustafa Andkhoie, Dana Ramsay, Mohsen Yaghoubi, Megan Steeves, Michael Szafron and Marwa Farag*

\begin{abstract}
Background: Perceived health status indicates people's overall perception of their health, including both physical and psychological dimensions. The aim of this study was to examine the determinants of self-perceived health for Canadians aged 40 and older using data from the Canadian Community Health Survey (2010).

Methods: Multiple logistic regression models were employed to identify factors associated with self-perceived health in two age groups: Adults aged 65+ and Adults aged 40-64.

Results: We found that higher income was significantly associated with better health status while chronic conditions and stress were associated with worse health status. In the 40-64 and 65+ age groups, individuals in the highest income bracket were 4.65 and 1.94 times, respectively, more likely to report better health than individuals in the lowest income bracket. The difference in the level of income associated health inequities between the two age groups point to the need for understanding the reasons behind lower inequities among seniors and how much the social protections provided by the Canadian government to seniors contribute to lowering inequities.

Conclusions: Though Canada has a national public health insurance system providing coverage to all Canadians, health inequities associated with income persist providing further evidence of the importance of the social determinants of health. Examining the extent of these inequities and what factors influence them helps direct policy attention. In addition to documenting inequities, this paper discusses policy options for reducing the identified inequities.
\end{abstract}

Keywords: Self-perceived health, Chronic disease, Stress, Social determinants of health, Older adults, Healthy public policies

\section{Background}

There is an urgent need for health systems to have timely information on the needs and demands of the population accessing its services. Evidence from existing studies supports the use of individual ratings [1-3] to approximate self-determined perception of health status [4, 5]. Selfperceived health status is a predictor of morbidity and mortality [6-11], physical functioning [12, 13], and utilization of health services [14-16]. Furthermore, self-perceived health status ratings are highly correlated to physician assessments of health conditions $[17,18]$. Finally, it is very

* Correspondence: marwa.farag@usask.ca

School of Public Health, University of Saskatchewan, 104 Clinic Place, Room 3334, Saskatoon SK S7N 5E3, Canada important to assess the extent to which self-perceived health inequities exist and what drives them.

The Canadian government has collected survey data on self-perceived health and associated outcomes and health service utilization patterns for several decades. A 2001 Health Report prepared by Statistics Canada demonstrated that both social and psychological factors are predictors of self-perceived health status [19]. Improved understanding of the determinants of self-perceived health could be used to inform health promotion activities.

More recently, attention has been paid to how selfperceived health changes over time and varies across age groups. Such insights are increasingly important in light of the demographic changes associated with the maturation of

(c) The Author(s). 2017 Open Access This article is distributed under the terms of the Creative Commons Attribution 4.0 International License (http://creativecommons.org/licenses/by/4.0/), which permits unrestricted use, distribution, and reproduction in any medium, provided you give appropriate credit to the original author(s) and the source, provide a link to the Creative Commons license, and indicate if changes were made. The Creative Commons Public Domain Dedication waiver (http://creativecommons.org/publicdomain/zero/1.0/) applies to the data made available in this article, unless otherwise stated. 
Canada's "baby boom" [20, 21]. As perceived health status impacts the demand for health services, access to this information will permit planners to better meet the changing needs of an aging population [22, 23]. We also examined the factors associated with self-perceived health to identify the extent to which inequities exist and what drives them. To address inequities, we need to clearly understand what factors contribute to health inequities in the Canadian context and by how much.

\section{Methods}

This study used data from the 2010 Canadian Community Health Survey (CCHS). For more information regarding the survey methodology, please refer to the website provided [24]. Survey weights, provided by Statistics Canada were used to account for oversampling and under sampling as described by Statistics Canada [24, 25]. Stata version 12.1 was used to conduct all analyses presented in this study. The level of significance was set at 0.05 .

Our outcome of interest was dichotomized selfperceived health categorized as following: Good health (1) if respondents answered excellent, very good or good to the following question "In general would you say your health is?" and Less than good health (0) if respondents answered fair or poor to the same question. In this way, we identified those conditions associated with less than "good" perceived health. The study variables were selected from the 2010 CCHS based on the results of previous studies that identified major determinants of perceived health status [1-4]. The selected factors were grouped into three broad categories according to the format denoted in the 2010 CCHS, and include (a) social determinants, (b) psychological determinants and (c) physiological conditions in addition to control variables (age and sex).

Inclusion of social determinants as model variables was used to estimate the association of self-perceived health with social factors, including: level of education (less than secondary, secondary grad, other post secondary and post secondary grad); household income $(<\$ 20,000$, $\$ 20,000-\$ 39,999, \$ 40,000-\$ 59,999, \$ 60,000-\$ 79,999$ and $\$ 80,000$ or more); and marital status (married, living common-law, widowed, separated, divorced or single/ never married). To assess the relationship between selfperceived health and mental health factors, perceived stress was included as a model variable under the psychological determinants category. According to the CCHS, perceived stress was defined by respondents as the amount of stress they experience most days (not at all stressful, not very stressful, a bit stressful, quite a bit stressful or extremely stressful). Lastly, physiological conditions were included based on CCHS's classification of chronic conditions. Conditions classified in this way include asthma, arthritis, hypertension, diabetes, heart disease, cancer and anxiety disorder, to which respondents indicated having the condition or not.

We used a purposeful model selection strategy to fit the final logistic regression models. First, univariate analysis was conducted for each independent variable. Additionally, a standard contingency table was created for each categorical variable to determine if the cell frequency was equal to zero for either of the model's outcomes (i.e. "good health" or "poor health"). Variables were selected for inclusion if they contributed to the model (i.e., with a $P$ value less than 0.20). Based on the results of the univariate analyses, marital status was excluded because it did not contribute to the model for either the 40-64 age group $(0.89 \geq 0.25)$ or the 65 and older age group $(0.73 \geq 0.25)$. Full results of the univariate analyses are shown in Table 1. Second, two multivariate regression analysis models were used: (1) multiple logistic regression model nested within age group 65 and older and (2) multiple logistic regression model nested within age group 40-64. In model 1 above, 12,044 observations were used (23.5\% missing) in the final model. In model 2 above, 20,365 observations were used (15.0\% missing) in the final model. We performed the Hosmer-Lemeshow test to assess the goodness of fit of the logistic regression models; the $p$-values for our models were 0.35 and 0.43 for the 40-64 years model and 65 above model respectively, which indicates that the two models fit the data well. In addition, we used the Linktest to examine model specification; the $p$-values for the hatsq were 0.24 for the $40-46$ years model and 0.36 for the 65 above model, which means that there is no specification error.

\section{Results}

In the 40-64 age group, $86.8 \%$ of all respondents reported good health and $13.3 \%$ reported less than good health. Among those who reported less than good health, 48.4\% were female and 51.5\% were male. In the 65 and above age group, $75.6 \%$ of all respondents reported good health and $24.3 \%$ reported less than good health. 54.7 of those who reported less than good health were female and $45.2 \%$ were male.

Significant associations between self-reported health status and select social determinants, psychological determinants and physiological conditions are presented for both the younger age group (40-64 years) and the older age group (65+ years). In general, self-reported health status was inversely correlated with age. In the older age group (65+ years), the absence of chronic health conditions was strongly predictive of good selfreported health. The absence of cancer $(\mathrm{OR}=3.18)$, heart disease $(\mathrm{OR}=2.85)$ and diabetes $(\mathrm{OR}=2.31)$ demonstrated the strongest associations with self-reported "good health" in this age category. 


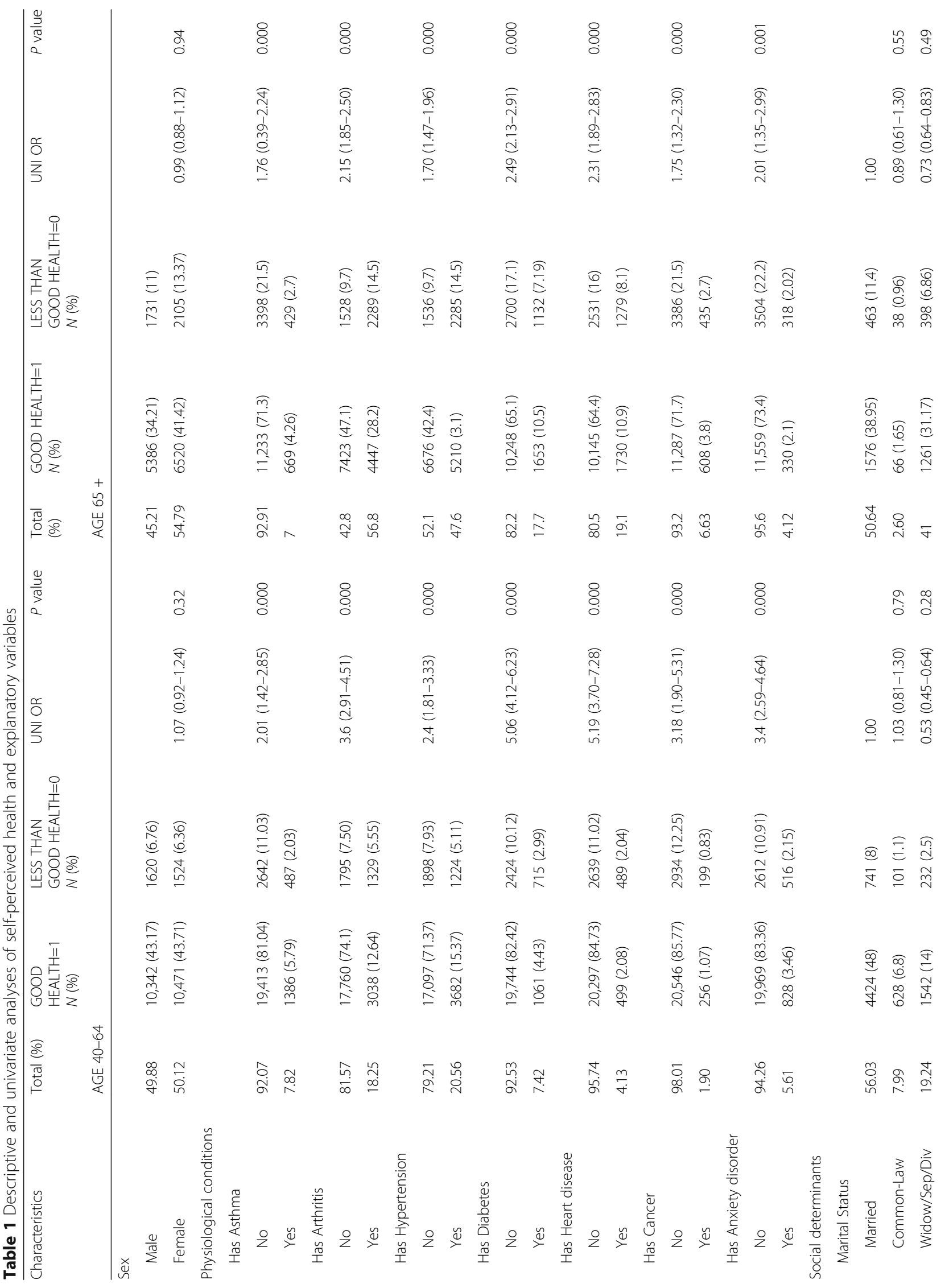




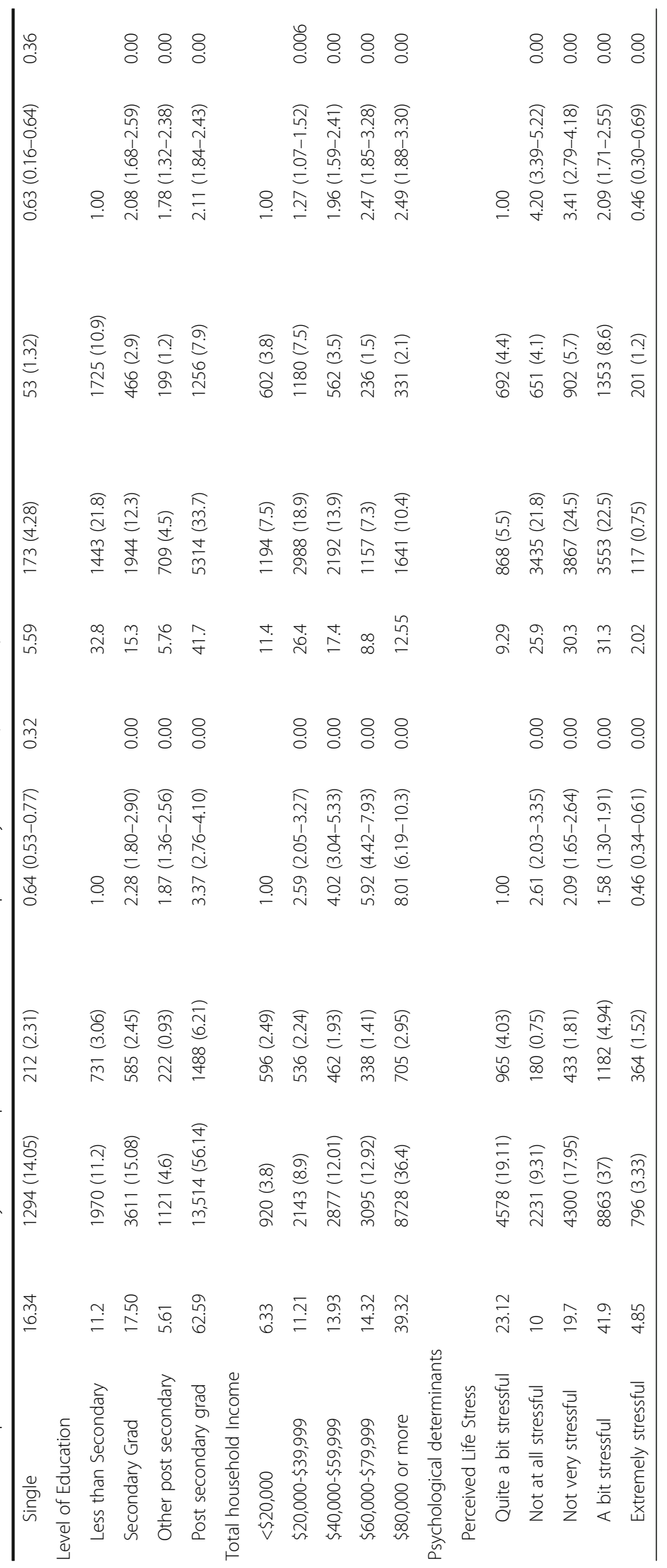


In the younger age group (40-64 years), the absence of chronic health conditions was even more strongly predictive of self-reported "good health". As with older individuals, the absence of cancer $(\mathrm{OR}=4.98)$, heart disease $(\mathrm{OR}=4.71)$ and diabetes $(\mathrm{OR}=4.14)$ were most strongly associated with perceived "good health" (see Table 2).
In the 65+ age group, individuals in the highest income bracket $(\$ 80,000+)$ were 1.94 times more likely to report "good health" than those individuals in the lowest income bracket $(\$ 0-20,000)$. This association was much stronger $(\mathrm{OR}=4.65)$ in the younger age group; this is an important finding because it may be an indication that

Table 2 Odds ratios of variables associated with good self-perceived health for Canadians aged 40-46 and 65+ using multivariate logistic regressions

\begin{tabular}{|c|c|c|c|c|}
\hline \multirow{2}{*}{$\begin{array}{l}\text { Variables } \\
\text { Good Health (1) vs. Less than good (0) }\end{array}$} & \multicolumn{2}{|l|}{ AGE 40-64 } & \multicolumn{2}{|l|}{ AGE 65+ } \\
\hline & $\overline{\mathrm{OR}}$ & $P$ & $\overline{\mathrm{OR}}$ & $P$ \\
\hline \multicolumn{5}{|l|}{ Sex } \\
\hline Female & $1.27(1.08-1.50)$ & 0.001 & $1.37(1.12-1.66)$ & 0.001 \\
\hline \multicolumn{5}{|l|}{ Physiological conditions } \\
\hline \multicolumn{5}{|l|}{ Has Asthma } \\
\hline No & $1.43(1.16-1.76)$ & 0.001 & $1.81(1.56-2.52)$ & 0.000 \\
\hline \multicolumn{5}{|l|}{ Has Arthritis } \\
\hline No & $2.93(2.42-3.55)$ & 0.000 & $1.99(1.73-2.28)$ & 0.000 \\
\hline \multicolumn{5}{|l|}{ Has Hypertension } \\
\hline No & $1.59(1.32-1.91)$ & 0.000 & $1.38(1.20-1.59)$ & 0.000 \\
\hline \multicolumn{5}{|l|}{ Has Diabetes } \\
\hline No & $4.14(3.19-5.35)$ & 0.000 & $2.31(1.83-2.61)$ & 0.000 \\
\hline \multicolumn{5}{|l|}{ Has Heart disease } \\
\hline No & $4.71(3.22-6.28)$ & 0.000 & $2.85(2.10-2.97)$ & 0.000 \\
\hline \multicolumn{5}{|l|}{ Has Cancer } \\
\hline No & $4.98(3.5-7.1)$ & 0.000 & $3.18(1.81-3.30)$ & 0.000 \\
\hline \multicolumn{5}{|l|}{ Has Anxiety disorder } \\
\hline No & $2.8(2.19-3.65)$ & 0.000 & $2.02(1.50-2.71)$ & 0.000 \\
\hline \multicolumn{5}{|l|}{ Social determinants } \\
\hline \multicolumn{5}{|l|}{ Level of Education } \\
\hline Less than secondary & 1 & & 1 & \\
\hline Secondary Grad & $1.45(1.08-1.95)$ & 0.01 & $1.84(1.47-2.30)$ & 0.000 \\
\hline Other post secondary & $1.37(0.98-1.90)$ & 0.05 & $1.72(1.24-2.37)$ & 0.001 \\
\hline Post secondary grad & $2.07(1.65-2.60)$ & 0.00 & $1.79(1.51-2.11)$ & 0.000 \\
\hline \multicolumn{5}{|l|}{ Total household Income } \\
\hline$<\$ 20,000$ & 1 & & 1 & \\
\hline$\$ 20,000-\$ 39,999$ & $2.26(1.69-3.03)$ & 0.000 & $1.17(0.95-1.44)$ & 0.13 \\
\hline$\$ 40,000-\$ 59,999$ & $2.73(1.98-3.76)$ & 0.000 & $1.52(1.18-1.95)$ & 0.001 \\
\hline$\$ 60,000-\$ 79,999$ & $3.97(2.83-5.55)$ & 0.000 & $1.78(1.28-2.46)$ & 0.001 \\
\hline$\$ 80,000$ or more & $4.65(3.23-6.05)$ & 0.000 & $1.94(1.37-2.67)$ & 0.000 \\
\hline \multicolumn{5}{|l|}{ Psychological determinants } \\
\hline \multicolumn{5}{|l|}{ Perceived Life Stress } \\
\hline Quite a bit & 1 & & 1 & \\
\hline Not at all & $2.78(2.25-4.05)$ & 0.000 & $3.83(3.02-4.92)$ & 0.000 \\
\hline Not stressful & $2.11(1.59-2.82)$ & 0.000 & $2.97(2.35-3.74)$ & 0.000 \\
\hline A bit stressful & $1.51(1.21-1.89)$ & 0.000 & $2.04(1.63-2.56)$ & 0.000 \\
\hline Extremely stressful & $0.64(0.47-0.86)$ & 0.004 & $0.51(0.31-0.83)$ & 0.007 \\
\hline
\end{tabular}


the protections available to seniors, and not available to the younger age group, are somewhat effective in protecting them.

The relationship between the level of education and self-reported health was also consistent with our expectations. More education seems to be associated with reporting better health. In the 65 and older age group, individuals who graduated from secondary school were more likely to report "good health" than those with less than secondary education $(\mathrm{OR}=1.84)$. Among participants in the younger age group, secondary school graduates were also more likely to report "good health" compared to individuals with less than secondary education $(\mathrm{OR}=1.45)$. Table 2 summarizes the odds ratio estimates for select social factors.

Individuals in the older age group (65+) who described their life as "not at all stressful" were 3.83 times more likely to report "good health" than those who described their life as "quite a bit stressful"; this association was also strong in the 40-64 age group ( $\mathrm{OR}=2.78)$.

\section{Discussion}

The first objective of this study was to identify determinants of self-perceived health in Canada in two age groups (40-64 years and 65 and older years). Significant determinants of self-reported health found among both age groups include the presence of chronic conditions, household income and perceived life stress.

In both age groups, the presence of chronic health conditions such as cancer, heart disease and diabetes resulted in statistically lower odds of reporting "good health". Comparing the two age groups, individuals in the younger age group (40-64) demonstrated lower odds of self-perceived "good health" for each chronic condition compared to their counterparts in the older age group $(65+)$ with similar conditions. Prior research has demonstrated that chronic disease and comorbid conditions significantly contribute to poorer self-perceived health $[26,27]$. This is because self-perceived health is not only affected by medical facts and biological health but also how illness affects day-to-day living [28-30]. It is widely accepted that self-perceived health is a multidimensional construct determined not only by the absence of health problems but also functional, coping and wellbeing factors [28, 31, 32]. Additionally, self-perceived health may be influenced by family history and a personal estimate of longevity [6]. Idler and Benyamini [33] proposed that self-perceived health was a dynamic measure, accounting not only for present levels of health but a judgment of the trajectory of future health. These findings may partially explain why participants in both age groups with chronic diseases were less likely to report "good health": that is, because chronic diseases impede on functional, coping and wellbeing factors, individuals may recognize these shortcomings in the way they perceive their own health. The literature also provides some insight into why the younger age group (40-64) with chronic conditions may be less likely to report "good health" compared to participants in the older age group (65 and older). One such insight is that experiences of chronic conditions among the younger age group (40-64) may result in a poorer judgement of the trajectory of future health as these experiences will likely last for a larger portion of an individual's life course.

We found that across both age groups, higher levels of stress were associated with lower odds of self-perceived "good health". However, the older group was even less likely to report "good health" in the higher stress categories. This is unsurprising given that psychosocial factors, notably stress, have been historically linked to poorer health perceptions [34]. The mechanism by which stress is linked to poorer health perceptions may relate to the ways stress influences physical health. Distress, or feeling stressed, may increase the risk of coronary heart disease, $[35,36]$ may play a role in the development of metabolic disorders, $[37,38]$ and can reduce the body's immune response [39]. Distress is also associated with higher allcause mortality and exhibits a dose-response relationship when adjusting for comorbid conditions, behaviours and socioeconomic status (SES) [40]. Older adults in the 65+ age group who experienced higher stress levels were more likely to report poorer health than their highly stressed counterparts in the younger age group (45-64). Choi and Jun [41] argue that older adults experience a number of unfamiliar stressors unique to ageing, including loneliness, having to depend on others for support, and caregiving for a spouse or relative, which could contribute to higher odds of reporting "poor health".

As for the relationship between income and selfperceived health, there is a large body of research documenting the relationship between SES and self-perceived health, whether using measures of income, occupation or education as a SES metric [42, 43]. Our results demonstrated that respondents in both age groups in the lowest quintile of household income $(<\$ 20,000)$ were more likely to report poorer health. This relationship could be explained either by health selection or social causation. Health selection proposes that the relationship between lower SES strata and poorer self-perceived health is due to the detrimental effect that poor health has on educational and occupational attainment, thereby precipitating a downward spiral in SES [44]. This model posits that respondents in both age groups in the lowest quintile of household income $(<\$ 20,000)$ are also those already in poor health, and this is reflected in their reports of self-perceived health. In contrast, social causation models explain that persons in lower SES strata are subject to conditions such as poor housing, poor 
nutrition, inadequate education and access to medical services that trigger poorer health outcomes [45]. According to this model, the conditions experienced by respondents in both age groups in the lowest quintile of household income $(<\$ 20,000)$ are associated with poor health, and so living in these conditions negatively impacts self-perceived health. Despite contrasting theories as to the directionality of the relationship, our results are complimentary to the widely accepted relationship between income and self-perceived health presented in the literature.

Our findings are likely interrelated and reflect the complexities of health, perceptions of health and its relationship with social, psychological and physiological determinants. For example, another mechanism by which income may affect self-perceived health is through the relationship between income security and distress. Orpana et al. [46] demonstrated evidence that the measure of income in the form of financial stability may influence level of distress and, therefore, alter self-perceived health. This mechanism showcases interrelations between self-perceived health and two distinct categories of determinants: social and psychological. This level of analysis and assessment will likely be necessary moving forward when addressing self-perceived health disparities.

Our findings extend the existing literature by focusing specifically on the Canadian population and demonstrate that among middle-aged and elderly Canadians, the presence of chronic conditions, lower household income and psychological distress result in higher odds of lower self-perceived health status.

\section{Limitations}

The 2010 Canadian Community Health Survey (CCHS) is a cross-sectional study conducted across all 10 Canadian provinces and three territories [25]. Its cross-sectional design only allows for identification of associations, but not causation. Furthermore, the CCHS is limited as it directly excludes certain population groups such as persons living on reserves or other Aboriginal settlements, full-time members of the Canadian Forces, the institutionalized population and inhabitants within the Québec health regions: Région de Nunavik and Région des Terres-Criesde-la-Baie-James. Indirectly, the CCHS survey excludes Canadians without stable housing and/or a registered home telephone number. Finally, since participation is voluntary, the data collected may reflect a certain level of volunteer bias.

Self-perceived health, although proven a good predictor of health status and mortality, [6-9] is still assumed to be an inferior indicator of population health compared to objective health measures [47]. Some limitations of the self-perceived health measure include reporting bias and difficulties interpreting this measure across varying age ranges and cultural groups. Although there are limitations, a recent study by Schnittker and Bacak [48] suggests that the self-perceived health measure is becoming increasingly more predictive of objective health and mortality due to the widespread availability of health information in developed countries. Finally, we were not able to include some variables, such as "social ties", because they were not available in the dataset.

\section{Conclusions and policy implications}

Findings from longitudinal analyses have demonstrated the power of the self-perceived health measure in predicting the incidence of chronic disease, [7-9] recovery from illness, [49] functional decline, [50] use of medical services, $[14,15]$ and even mortality [6-9].

The findings of this study indicate that chronic conditions, income and stress all have significant influences on the self-perceived health status of middle-aged and elderly Canadians. Since self-perceived health status within a population can affect medical service utilization and mortality rates, it is critical that policymakers identify and employ measures to alleviate the negative effects of these factors on individuals' self-perceived health status. The results also highlight the importance of social determinants of health. It is clear that in spite of having a universal adequate health insurance system, inequities associated with income persist in Canada.

Lorig et al. [51] found that a chronic disease selfmanagement program over 2 years in persons 40 years and older reduced medical service utilization, improved health distress and improved patient self-efficacy. Weighing the costs and benefits of such an intervention, Lorig et al demonstrated that their intervention prevented approximately 2.5 visits for medical services (emergency room visits \& physician outpatient visits) per participant and reduced hospitalization stays by 0.5 days per participant. This reduced use of medical services saved roughly $\$ 590$ in healthcare costs per participant while the intervention itself cost between $\$ 70$ 200 per participant. The former is just one example of a targeted program or policy, which could help improve health among a specific population group while concurrently reducing health care costs.

Other policies to address income stability, financial security and distress among older Canadians could also serve to improve the health status of this population group while simultaneously reducing health care costs. When looking at financial security, although Canada has one of the lowest elderly poverty rates in the developed world, elderly women living alone (widowed/divorced/ never married) tend to be at the highest risk of being impoverished due to pension allowances tied to previous employment [52]. Inadequate financial security in later life can severely limit access to resources, which may 
improve health and quality of life, such as transportation, social participation and adequate nutrition. Also, studies have shown a link between financial insecurity among elderly and increased levels of distress [53]. Policies concerning elderly poverty should take this into consideration and poverty among elderly women/men living alone could be reduced through increased government transfers to this population. It is important for policymakers to incorporate and address the social determinants of health in order to facilitate healthy public policy.

In conclusion, the presence of chronic conditions, distress and lower household income negatively impacts the odds of reporting "good" health among middle-aged and elderly Canadians. Targeted policies addressing these factors are likely to lead to significant reductions in identified health inequities.

\section{Acknowledgements}

Not applicable.

\section{Funding}

This study was not funded by a grant.

\section{Availability of data and materials}

The databases analyzed during the current study are publicly available from Statistics Canada.

\section{Authors' contributions}

All authors participated in all stages of the preparation of the manuscript and approved its final version for submission. RW conceived the research question. RO and RW conducted the review of the literature and assisted with the writing and editing of the paper. $\mathrm{XL}, \mathrm{MA}$, and $\mathrm{MY}$ contributed equally to conducting the statistical analyses. WIAB, MST, and DR participated in writing and interpretation of findings. MS supervised developing the statistical methodology, analyses and the interpretations of the associated results. MF supervised the analysis and interpretation of the findings as well as the writing of the paper. MF were responsible for the critical review of the manuscript. All authors read and approved the final manuscript.

\section{Competing interests}

The authors declare that they have no competing interests.

\section{Consent for publication}

Not applicable.

\section{Ethics approval and consent to participate}

This study did not require ethics approval. Not applicable.

\section{Publisher's Note}

Springer Nature remains neutral with regard to jurisdictional claims in published maps and institutional affiliations.

Received: 19 November 2016 Accepted: 31 May 2017 Published online: 06 June 2017

\section{References}

1. Damian J, Ruigomez A, Pastor V, Martin-Moreno J. Determinants of self assessed health among Spanish older people living at home. J Epidemiol Community Health. 1999:53(7):412-6.

2. Yu E, Kean Y, Slymen D, Liu W, Zhang M, Katzman R. Self-perceived health and 5-year mortality risks among the elderly in Shanghai, China. Am J Epidemiol. 1998;147(9):880-90.
3. Chan K, Pang W, Ee C, Ding Y, Choo P. Self-perception of health among elderly community dwellers in Singapore. Ann Acad Med Singapore. 1998; 27(4):461-7.

4. Cott C, Gignac M, Badley E. Determinants of self rated health for Canadians with chronic disease and disability. J Epidemiol Community Health. 1999; 53(11):731-6.

5. Cousins S. Validity and reliability of self-reported health of persons aged 70 and older. Health Care Women Int. 1997;18(2):165-74.

6. Idler E, Kasl S. Health perceptions and survival: Do global evaluations of health status really predict mortality? J Gerontol. 1991;46(2):S55-65.

7. Kaplan G, Goldberg D, Everson S, Cohen R, Salonen R, Tuomilehto J, et al. Perceived health status and morbidity and mortality: evidence from the Kuopio ischaemic heart disease risk factor study. Int J Epidemiol. 1996;25(2): 259-65.

8. Ferraro K, Kelley-Moore J. Self-rated health and mortality among black and white adults: examining the dynamic evaluation thesis. J Gerontol B Psychol Sci Soc Sci. 2001:56(4):S195-205.

9. Ferraro K, Farmer M, Wybraniec J. Health trajectories: long-term dynamics among black and white adults. J Health Soc Behav. 1997;38(1):38.

10. Ganna A, Ingelsson E. 5-year mortality predictors in 498103 UK Biobank participants: a prospective population-based study. Lancet. 2015;386:533-40.

11. Stenholm S, Kivimaki M, Jylha M, Kawachi I, Westerlund H, Pentti J, et al. Trajectories of self-rated health in the last 15 years of life by cause of death. Eur J Epidemiol. 2016;31(2):177-85.

12. Menec V, Chipperfield J. The interactive effect of perceived control and functional status on health and mortality among young-old and old-old adults. J Gerontol B Psychol Sci Soc Sci. 1997;52B(3):118-26.

13. Roos E, Lahelma E, Saastamoinen P, Elstad J. The association of employment status and family status with health among women and men in four Nordic countries. Scand J Public Health. 2005;33(4):250-60.

14. Miilunpalo S, Vuori I, Oja P, Pasanen M, Urponen H. Self-rated health status as a health measure: The predictive value of self-reported health status on the use of physician services and on mortality in the working-age population. J Clin Epidemiol. 1997;50(5):517-28.

15. Weinberger M, Darnell J, Tierney W, Martz B, Hiner S, Barker J, et al. Self-rated health as a predictor of hospital admission and nursing home placement in elderly public housing tenants. Am J Public Health. 1986; 76(4):457-9.

16. Best R, Souders DJ, Charness N, Mitzner TL, Rogers WA. The Role of Health Status in Older Adults' Perceptions of the Usefulness of eHealth Technology. In: Zhou J, Salvendy G. (eds) Human Aspects of IT for the Aged Population. Design for Everyday Life. ITAP 2015. Lecture Notes in Computer Science. Springer, Cham. 2015. vol 9194.

17. Larue A, Bank L, Jarvik U, Hetland M. Health in old age: How do physicians' ratings and self-ratings compare? J Gerontol. 1979:34(5):687-91.

18. Brown TN, Turner RJ, Moore TR. The multidimensionality of health: associations between allostatic load and self-report health measures in a community epidemiologic study. Health Sociol Rev. 2016;25(3):272-87.

19. Shields M, Shooshtari S. Determinants of self-perceived health. Health Rep. 2001;13(1):35-52.

20. Government of Canada. Chief public health officer's report on the state of health in Canada, 2014. Ottawa: Public Health in the Future; 2014. Available online at: http://www.phac-aspc.gc.ca/cphorsphc-respcacsp/2014/assets/ pdf/2014-eng.pdf . Last accessed on 2015.

21. Schneider $E$. The aging of America. Impact on health care costs. JAMA. 1990;263(17):2335-40.

22. Canadian Health Services Research Foundation. Synthesis report - better with age: health systems planning for the aging population. Ottawa: CHSRF; 2011. Available online at: http://www.cfhi-fcass.ca/Libraries/Aging_ roundtable_reports/0604-AGING_RNDTBLE-SNTHSS_FinalWEB.sflb.ashx. Last accessed 2015.

23. Badley EM, Canizares M, Perruccio AV, Hogg-Johnson SH, Gignac MA. Benefits gained, benefits lost: comparing baby boomers to other generations in a longitudinal cohort study of self-rated health. Milbank Q. 2015;93(1):40-72.

24. Statistics Canada. Community health survey - annual component (CCHS). 2011. Available online at: http://www23.statcan.gc.ca/imdb/p2SV. pl?Function=getSurvey\&SDDS=3226. Last accessed 19 Dec 2014.

25. Statistics Canada. Canadian community health survey - annual component (CCHS). 2014. Available online at: http://www23.statcan.gc.ca/imdb/p2SV. pl?Function=getSurvey\&ld=164081. Last accessed 19 Dec 2014. 
26. Hoeymans N, Feskens E, Kromhout D, van den Bos G. The contribution of chronic conditions and disabilities to poor self-rated health in elderly men. J Gerontol A Biol Sci Med Sci. 1999;54(10):501-6.

27. Arokiasamy P, Uttamacharya JK. Multi-morbidity, functional limitations, and self-rated health among older adults in India: cross-sectional analysis of LASI pilot survey, 2010. Sage Open. 2015;5(1):2158244015571640.

28. Bostan C, Oberhauser C, Stucki G, Bickenbach J, Cieza A. Biological health or lived health: which predicts self-reported general health better? BMC Public Health. 2014;14(1):189.

29. Uutela T, Kautianinen $H$, Jarvenpaa $S$, Hakala M, Hakkinen A. Self-rated health in patients with rheumatoid arthritis is associated with health-related quality of life but not with clinical variables. Scand J Rheumatol. 2016;45(4): 288-93.

30. Johnson R, Wolinsky F. The structure of health status among older adults: disease, disability, functional limitation, and perceived health. J Health Soc Behav. 1993;34(2):105.

31. Gallagher JE, Wilkie AA, Cordner A, Hudgens EE, Ghio AJ, Birch RJ, Wade TJ. Factors associated with self-reported health: implications for screening level community-based health and environmental studies. BMC Public Health. 2016;16(1):640

32. Meng X, D'Arcy C. Determinants of self-rated health among Canadian seniors over time: a longitudinal population-based study. Soc Indic Res. 2016;126(3):1343-53.

33. Idler E, Benyamini Y. Self-rated health and mortality: a review of twentyseven community studies. J Health Soc Behav. 1997;38(1):21.

34. Farmer M, Ferraro K. Distress and perceived health: mechanisms of health decline. J Health Soc Behav. 1997;38(3):298.

35. Stansfeld S. Psychological distress as a risk factor for coronary heart disease in the Whitehall II study. Int J Epidemiol. 2002;31(1):248-55.

36. Booth J, Connelly L, Lawrence M, Chalmers C, Joice S, Becker C, et al. Evidence of perceived psychosocial stress as a risk factor for stroke in adults: a meta-analysis. BMC Neurol. 2015;15(1):233.

37. Whisman M, Uebelacker L, Settles T. Marital distress and the metabolic syndrome: linking social functioning with physical health. J Fam Psychol. 2010;24(3):367-70.

38. Rosenbaum S, Stubbs B, Ward PB, Steel Z, Lederman O, Vancampfort D. The prevalence and risk of metabolic syndrome and its components among people with posttraumatic stress disorder: a systematic review and metaanalysis. Metabolism. 2015;64(8):926-33.

39. Kemeny M, Schedlowski M. Understanding the interaction between psychosocial stress and immune-related diseases: a stepwise progression. Brain Behav Immun. 2007;21(8):1009-18.

40. Russ T, Stamatakis E, Hamer M, Starr J, Kivimaki M, Batty G. Association between psychological distress and mortality: individual participant pooled analysis of 10 prospective group studies. BMJ. 2012;345(4):4933.

41. Choi N, Jun J. Life regrets and pride among low-income older adults: relationships with depressive symptoms, current life stressors and coping resources. Aging Ment Health. 2009;13(2):213-25.

42. Adler N, Ostrove J. Socioeconomic status and health: what we know and what we don't. Ann N Y Acad Sci. 1999:896(1):3-15.

43. Nayak S, Hubbard A, Sidney S, Syme SL. Characteristics associated with selfrated health in the CARDIA study: contextualizing health determinants by income group. Prev Med Rep. 2016:4:199-208.

44. Manor O, Matthews S, Power C. Health selection: the role of inter- and intragenerational mobility on social inequalities in health. Soc Sci Med. 2003; 57(11):2217-27.

45. Goldman N. Social factors and health: the causation-selection issue revisited. Proc Natl Acad Sci. 1994;91(4):1251-5.

46. Orpana H, Lemyre L, Gravel R. Income and psychological distress: the role of the social environment. Health Rep. 2009;20(1):1-7.

47. Kuhn R, Rahman O, Menken J. Survey measures of health: how well do selfreported and observed indicators measure health and predict mortality? In: Cohen B, Menken J, editors. Aging in Sub-Saharan Africa: recommendation for furthering research. Washington (DC): National Academies Press (US); 2006. p. 314-44.

48. Schnittker J, Bacak V. The increasing predictive validity of self-rated health PLoS ONE. 2014;9(1):e84933. doi:10.1371/journal.pone.0084933. Published online 2014 Jan 22

49. Wilcox V, KasI S, Idler E. Self-rated health and physical disability in elderly survivors of a major medical event. J Gerontol B Psychol Sci Soc Sci. 1996; 51B(2):96-104
50. Idler E. Survival, functional limitations, and self-rated health in the NHANES I epidemiologic follow-up study, 1992. Am J Epidemiol. 2000;152(9):874-83.

51. Lorig K, Ritter P, Stewart A, Sobel D, William Brown B, Bandura A, et al. Chronic disease self-management program. Med Care. 2001;39(11):1217-23.

52. Conference Board of Canada. Elderly poverty. Conference board of Canada report, January 2013. 2013. Available online at: http://www.conferenceboard. ca/hcp/details/society/elderly-poverty.aspx. Last accessed 4 Mar 2015.

53. Keith V. Gender, financial strain, and psychological distress among older adults. Res Aging. 1993;15(2):123-47.

\section{Submit your next manuscript to BioMed Central and we will help you at every step:}

- We accept pre-submission inquiries

- Our selector tool helps you to find the most relevant journal

- We provide round the clock customer support

- Convenient online submission

- Thorough peer review

- Inclusion in PubMed and all major indexing services

- Maximum visibility for your research

Submit your manuscript at www.biomedcentral.com/submit
) Biomed Central 